\title{
Modified Open Loop Control of a Matrix Converter Connected to Wind Energy System
}

\author{
Kotb B. Tawfiq, A.F. Abdou, E. E. EL-Kholy and S. S. Shokralla \\ Department of Electrical Engineering, Menoufia University, Menoufia, Egypt \\ kotbbasem29@yahoo.com, e.e.elkholy@ieee.org
}

\begin{abstract}
WECS) is bit by bit gaining interest as a suitable source of renewable energy. In this paper a direct AC-AC matrix converter is utilized to interface an isolated static load fed from WECS. A self-excited induction generator is utilized as it has many advantages in terms of ease of maintenance, self-protection against short circuits. This paper proposes a modified open loop control of matrix converter with indirect space vector modulation. The modified open loop provides constant output voltage and constant frequency even if the wind speed changed. Matrix converter (MC) is used rather than AC-DC-AC converter as it eliminates the bulky capacitors. Finally, simulation results for different operating points are displayed which are consistent with the expected results.
\end{abstract}

\section{INTRODUCTION}

Due to the continuous demand on electrical energy and environmental concerns, a lot of exertion is being made to create power from renewable sources of energy. The advantage of using renewable sources is absence of harmful emissions. Wind generators have been generally utilized in autonomous systems for feeding loads which fall outside the scope of the electrical network. There are two types of WT horizontal axis configuration or vertical axis configuration [1].As a result of the numerous advantages of using a self-excited induction generator in converting the captured mechanical energy from WT made it suitable for use in small and medium size WECS. Due to the low cost of SCIG compared to other types of electric machines make it suitable for isolated load application of WECS. SCIG also have the ability of self -protection against short circuits and doesn't require routine maintenance. $A C$ can be directly converted to $A C$ with different voltage rms value and different frequency by using a $M C$ without using any DC link[2,3]. And this is the bold feature of MC over rectifier-inverter converter, so MC can be considered an emerging alternative to the conventional rectifier- inverter converter [4-7]. Independent control on the output voltage magnitude and frequency can be provided by utilizing a MC. In addition to control the phase angle between input voltage and input current and unity input displacement factor can be achieved. Due to MC has a faster dynamic response, MC -based on WECSs has higher efficiency than conventional one. This paper introduces a static R-L load controlled by using a MC fed from WECS as shown in Fig. 1.This paper proposes a modified open loop control to provide constant output voltage and constant frequency even if the wind speed changed. First, a short description of WT is introduced, in addition to demonstrate how the wind energy can be ideally caught and changed over to electric energy. Secondly, a short description on operation of a SCIG is introduced. Third, indirect space vector control of matrix converter is presented. $M C$ is used to control load voltage and frequency. Fourth modified open loop control of matrix converter is introduced. Finally, simulation results for different operating points are displayed.

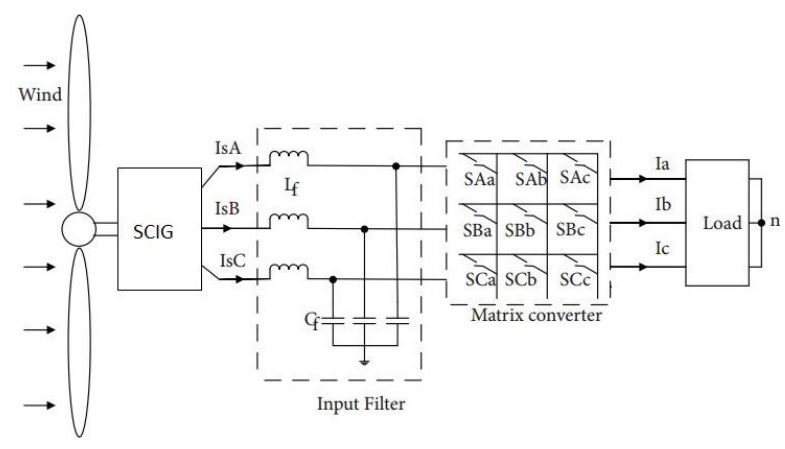

Fig. 1. matrix converter fed from wind turbine

\section{WIND TURBINE}

The produced mechanical power from turbine is given by (1).

$$
P_{m}=\frac{1}{2} \rho c_{p} A_{r} v_{w}^{3}
$$


$c_{p}(\lambda, \theta)=0.73\left(\frac{151}{\lambda_{i}}-0.58 \theta-0.002 \theta^{2.14}-13.2\right) e^{\frac{-18.4}{\lambda_{i}}}$

$$
\lambda_{i}=\frac{1}{\frac{1}{\lambda-0.02 \theta}-\frac{0.003}{\theta^{3}+1}}
$$

$$
\lambda=\frac{\omega_{\mathrm{r}} \mathrm{R}_{\mathrm{r}}}{\mathrm{v}_{\mathrm{w}}}
$$

Where $P_{m}$ represents the generated power, $v_{w}$ is the wind speed in $\mathrm{m} / \mathrm{s}, \rho$ is the air density in $\mathrm{g} / \mathrm{m}^{3}, A_{r}$ the turbine rotor area in $\mathrm{m}^{2},\left(A_{r}=\pi R_{r}^{2}\right.$, where $R_{r}$ is the rotor blade radius) and, $c_{p}$ a power coefficient. The power coefficient can be calculated as a function of tip speed ratio and rotor blade pitch angle $\theta$ according to (2) $\omega_{r}$ is the angular speed of the turbine shaft in $\mathrm{rad} / \mathrm{s}$. In this paper assumes a fixed rotor pitch angle $(\theta=0)$. The previous four equation give, the generated mechanical power by the wind turbine at a given wind velocity is a function of the shaft speed. Figure 2 demonstrates the generated mechanical power with turbine speed at various wind velocity [1].

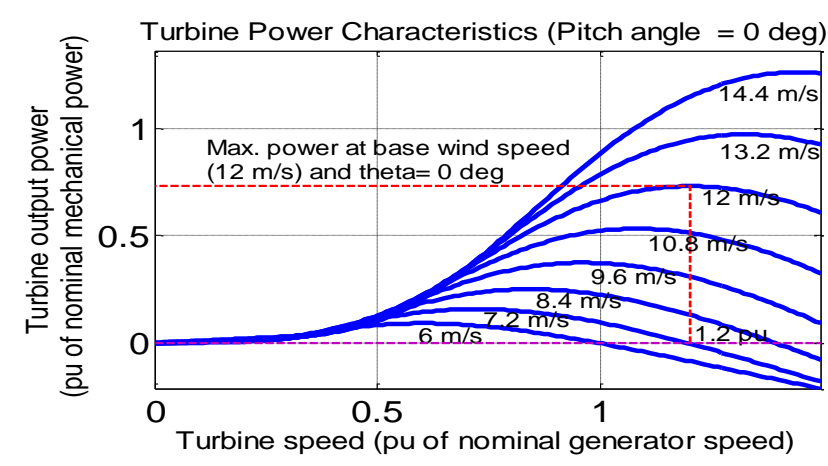

Fig. 2 mechanical power with turbine spee

\section{INDUCTION GENERATOR}

Induction machine can be utilized as an induction generator as well as induction motor without making any internal modification. Reactive power required for induction generator can be achieved by connecting a capacitor bank across the stator terminals. When the rotor is rotated by a speed greater than synchronous speed, a little voltage is produced over the stator terminals because of residual magnetism. A capacitor current will be produced due to this small generated voltage, and reactive power which required for magnetization will increase. Induction generators are suitable in wind turbines as they produce valuable power even at different rotor speeds. Neither commutator nor brush arrangement is required for Induction generators compared to synchronous generators. Figure 3 shows the equivalent circuit of induction generator [1].

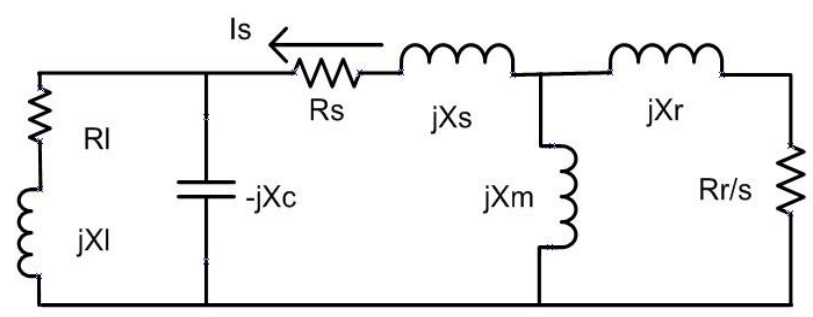

Fig. 3 one phase equivalent circuit of induction generator

$$
\begin{aligned}
& \left\{\begin{array}{l}
V_{s}^{a b c} \\
0^{a b c}
\end{array}\right\}=\left[\begin{array}{cc}
r_{s}^{a b c} & 0 \\
0 & r_{r}^{a b c}
\end{array}\right]\left\{\begin{array}{l}
i_{s}^{a b c} \\
i_{r}^{a b c}
\end{array}\right\}+\frac{d}{d t}\left\{\begin{array}{l}
\lambda_{s}^{a b c} \\
\lambda_{r}^{a b c}
\end{array}\right\} \\
& V_{s}^{a b c}=\left[\begin{array}{l}
v_{s a} \\
v_{s b} \\
v_{s c}
\end{array}\right], \quad V_{r}^{a b c}=\left[\begin{array}{l}
v_{r a} \\
v_{r b} \\
v_{r c}
\end{array}\right], \quad i_{s}^{a b c}=\left[\begin{array}{l}
i_{s a} \\
i_{s b} \\
i_{s c}
\end{array}\right], \quad i_{r}^{a b c}= \\
& {\left[\begin{array}{l}
i_{r a} \\
i_{r b} \\
i_{r c}
\end{array}\right]} \\
& r_{s}^{a b c}=\left[\begin{array}{ccc}
r_{s} & 0 & 0 \\
0 & r_{s} & 0 \\
0 & 0 & r_{s}
\end{array}\right], r_{r}^{a b c}=\left[\begin{array}{ccc}
r_{r} & 0 & 0 \\
0 & r_{r} & 0 \\
0 & 0 & r_{r}
\end{array}\right] \\
& L_{s s}^{a b c}=\left[\begin{array}{ccc}
L_{s s}+L_{l s} & L_{s m} & L_{s m} \\
L_{s m} & L_{s s}+L_{l s} & L_{s m} \\
L_{s m} & L_{s m} & L_{s s}+L_{l s}
\end{array}\right] \\
& L_{r r}^{a b c}=\left[\begin{array}{ccc}
L_{r r}+L_{l r} & L_{r m} & L_{r m} \\
L_{r m} & L_{r r}+L_{l r} & L_{r m} \\
L_{r m} & L_{r m} & L_{r r}+L_{l r}
\end{array}\right] \\
& L_{s r}^{a b c}=\left\{L_{r s}^{a b c}\right\}^{t}= \\
& L_{s r}\left[\begin{array}{ccc}
\cos \theta_{r} & \cos \left(\theta_{r}+\frac{2 \pi}{3}\right) & \cos \left(\theta_{r}-\frac{2 \pi}{3}\right) \\
\cos \left(\theta_{r}-\frac{2 \pi}{3}\right) & \cos \theta_{r} & \cos \left(\theta_{r}+\frac{2 \pi}{3}\right) \\
\cos \left(\theta_{r}+\frac{2 \pi}{3}\right) & \cos \left(\theta_{r}-\frac{2 \pi}{3}\right) & \cos \theta_{r}
\end{array}\right]
\end{aligned}
$$

Where, $r_{s}$ : resistance of the stator winding, $r_{r}$ : resistance of the rotor winding , $L_{s s}$ : self-inductance of the stator winding, $L_{s m}$ : Mutual inductance between stator winding, $L_{r r}$ : self-inductance of the rotor winding, $L_{r m}$ : Mutual inductance between rotor winding, $L_{s r}$ : Maximum value of Mutual inductance between stator and rotor winding, $L_{l s}$ : Leakage inductance of stator winding, The required capacitance value for exciting SCIG was calculated as in $[8,9]$. 


\section{MATRIX CONVERTER}

MC consists of a nine bidirectional switches which provide a direct connection between the three phase input voltage to the load without utilizing any dc link so MC can be manufactured in a simple and a compact form as shown on Fig. (4.a). . In 1976 Gigi and Pelly introduce the first principle of a MC.The first mathematical form of MC was introduced in 1980 by Venturini and switches are the primary disadvantage of this converter [10-15].

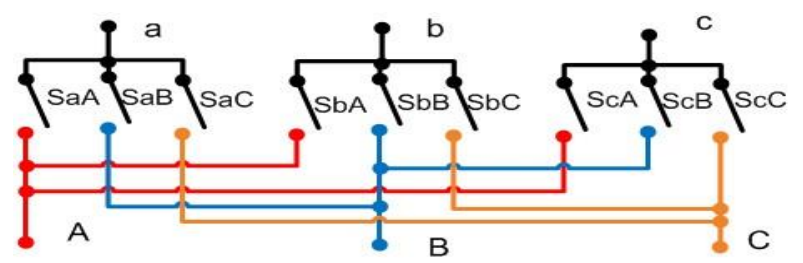

(a)

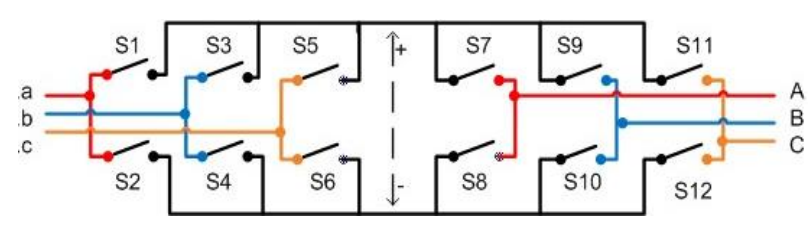

(b)

Fig .4: (a) Direct MC, (b) Indirect virtual DC-link MC

\section{A. MATRIX CONVERTER CONTROL}

This paper use indirect space vector control to control MC. MC consists of nine bidirectional switches which allow connection all input lines to all output lines. Indirect space vector control deals with $\mathrm{MC}$ as a rectifier-inverter with virtual DC link as in Fig. (4.b) which consists of two stages first is rectifier based on switches S1-S6, second is Inverter which has a three phases voltage source topology based on six switches S7-S12 [16].

$$
\begin{aligned}
& V_{D C}=E * V_{a b c}, V_{A B C}=N * V_{D C} \\
& V_{A B C}=\mathrm{N} * \mathrm{E} * V_{a b c}, \mathrm{~K}=\mathrm{N} * \mathrm{E} \\
& E=\left[\begin{array}{lll}
S_{1} & S_{3} & S_{5} \\
S_{2} & S_{4} & S_{6}
\end{array}\right], \quad N=\left[\begin{array}{ll}
S_{7} & S_{8} \\
S_{9} & S_{10} \\
S_{11} & S_{12}
\end{array}\right], \\
& K=\left[\begin{array}{lll}
S_{a A} & S_{b A} & S_{c A} \\
S_{a B} & S_{b B} & S_{c B} \\
S_{a c} & S_{b C} & S_{c C}
\end{array}\right]
\end{aligned}
$$

$$
\left[\begin{array}{lll}
S_{a A} & S_{b A} & S_{c A} \\
S_{a B} & S_{b B} & S_{c B} \\
S_{a C} & S_{b C} & S_{c C}
\end{array}\right]=\left[\begin{array}{ll}
S_{7} & S_{8} \\
S_{9} & S_{10} \\
S_{11} & S_{12}
\end{array}\right]\left[\begin{array}{lll}
S_{1} & S_{3} & S_{5} \\
S_{2} & S_{4} & S_{6}
\end{array}\right]
$$

Where $\mathrm{N}, \mathrm{E}$ and $\mathrm{K}$ represent inverter, rectifier and $\mathrm{MC}$ transfer function respectively. This strategy deal with $\mathrm{MC}$ as a rectifier-inverter converter so space vector of the inverter output voltage and space vector of rectifier input current can be decoupled to control direct MC[17]. As shown in (4) the output phases can be compounded by the product and sum of input phases through rectifier and inverter switches $S_{1}-S_{6}$ and $S_{7}-S_{12}$ respectively. The first row of the matrix in (10) show how to obtain output phase A from input phases $a, b$ and $c$ for direct MC using ISVM [18].

$$
\begin{aligned}
& {\left[\begin{array}{l}
V_{A} \\
V_{B} \\
V_{C}
\end{array}\right]=\left[\begin{array}{ll}
S_{7} & S_{8} \\
S_{9} & S_{10} \\
S_{11} & S_{12}
\end{array}\right]\left[\begin{array}{lll}
S_{1} & S_{3} & S_{5} \\
S_{2} & S_{4} & S_{6}
\end{array}\right]\left[\begin{array}{l}
\mathrm{v}_{\mathrm{a}} \\
\mathrm{v}_{\mathrm{b}} \\
\mathrm{v}_{\mathrm{c}}
\end{array}\right]} \\
& {\left[\begin{array}{l}
V_{A} \\
V_{B} \\
V_{C}
\end{array}\right]=\left[\begin{array}{lll}
S_{7} S_{1}+S_{8} S_{2} & S_{7} S_{3}+S_{8} S_{4} & S_{7} S_{5}+S_{8} S_{6} \\
S_{9} S_{1}+S_{10} S_{2} & S_{9} S_{3}+S_{10} S_{4} & S_{9} S_{5}+S_{10} S_{6} \\
S_{11} S_{1}+S_{12} S_{2} & S_{11} S_{3}+S_{12} S_{4} & S_{11} S_{5}+S_{12} S_{6}
\end{array}\right] *} \\
& {\left[\begin{array}{l}
v_{a} \\
v_{b} \\
v_{c}
\end{array}\right]}
\end{aligned}
$$

The switches of inverter can have only eight allowed combinations, to avoid short circuit on DC link. These eight permitted combinations is classified into six active nonzero output voltage vectors $V_{1}-V_{6}$ two zero output voltage vectors $V_{0}$ as in Fig. 5(a). For virtual rectifier there are allowed nine switching combinations to avoid an open circuit in rectifier. These nine combinations are divided into six active nonzero input current vectors $I_{1}-I_{6}$ and three zero input current vectors $I_{0}$ as shown in (Fig. $5(\mathrm{~b})$ ). The duty cycles $d_{\alpha}$ and $d_{\beta}$ of active vectors $V_{\alpha}$ and $V_{\beta}$ respectively for the reference voltage vector $V_{O}^{*}$ within a sector of the voltage hexagon can be derived from Fig. (6.a) [19].

$$
\begin{aligned}
& V_{o}^{*}=d_{\alpha} V_{\alpha}+d_{\beta} V_{\beta}+d_{z} \mathrm{~V}_{\mathrm{z}} \\
& d_{\alpha}=\frac{T_{\alpha}}{T_{s}}=m_{v} \cdot \sin \left(\frac{\pi}{3}-\theta_{v}\right) \\
& d_{\beta}=\frac{T_{\beta}}{T_{s}}=m_{v} \cdot \sin \left(\theta_{\mathrm{v}}\right) \\
& d_{z}=\frac{T_{z}}{T_{s}}=1-\left(d_{\alpha}+d_{\beta}\right)
\end{aligned}
$$




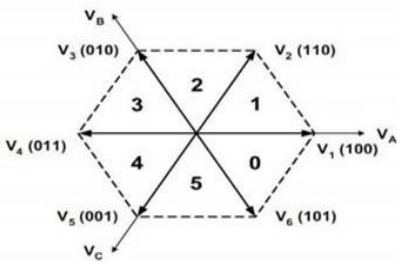

(a)

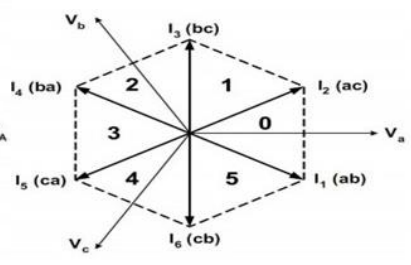

(b)
Fig.5. Hexagon of (a) the inverter, (b) the Rectifier

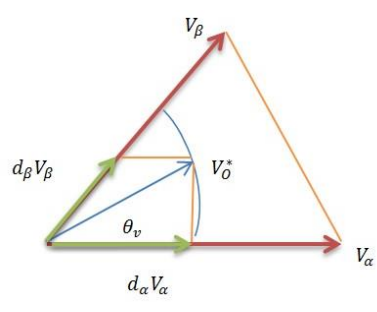

(a)

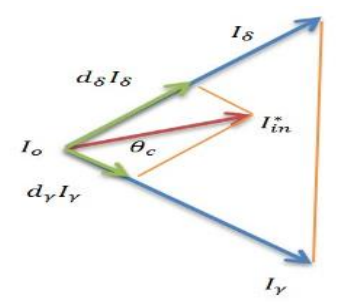

(b)
Fig. 6. Composition of reference: (a) output voltage vector (b) input current vector

Where, $T_{\alpha}, T_{\beta}$ and $T_{z}$ are the total duration times of the vectors $V_{\alpha}, V_{\beta}$ and $V_{z}$. The $I_{I N}^{*}$ can be obtained by impressing the adjacent active vectors $I_{\gamma}$ and $I_{\delta}$ with the duty cycles $d_{\gamma}$ and $d_{\delta}$ respectively as shown in Fig. (6.b). [1,2]

$I_{I N}^{*}=d_{\gamma} I_{\gamma}+d_{\delta} I_{\delta}+d_{o c} I_{0}$

$d_{\gamma}=m_{c} \cdot \sin \left(\frac{\pi}{3}-\theta_{c}\right)$

$d_{\delta}=m_{c} \cdot \sin \left(\theta_{c}\right)$

$$
d_{0 c}=1-\left(d_{\gamma}+d_{\delta}\right)
$$

\section{B. MODIFIED OPEN LOOP CONTROL OF MATRIX CONVERTER}

MC can control the rms value of the output voltage and frequency. But the output voltage of matrix converter in case of open loop control is a percent of the input voltage. If $q$ is the ratio between output voltage and input voltage, if $\mathrm{q}=0.4$ in open loop control, input voltage $=100 \mathrm{~V}$, the output voltage will be $40 \mathrm{~V}$ but with the required frequency. If the input voltage changes from $100 \mathrm{~V}$ to $50 \mathrm{~V}$ the output voltage will be $20 \mathrm{~V}$. If we need to obtain constant output voltage the q ratio must be changed from 0.4 to 0.8 so the $q$ ratio must be depend on the input voltage and this can be achieved by modified open loop control. Modified open loop control takes a signal from three-phase input voltage and $q$ ratio can be calculated as in (19).

From table 1 and Eq. (19) the ratio $q$ in case ofmodified open loop control depend on the input voltage where if the input voltage decreased the ratio $\mathrm{q}$ increased so that obtain a constant output voltage.Figure7.a shows the proposed modified open loop control of indirect space vector modulation. Figure7.b shows Matlab Simulink modification in the proposed modified open loop control of indirect space vector modulation

$$
q=\frac{V_{o u t}^{*}}{V_{I N}}
$$

Table 1. Modified open loop control and open loop control

\begin{tabular}{|l|l|l|l|l|}
\hline \multirow{2}{*}{$V_{\text {IN }}$} & \multicolumn{2}{|l|}{ Open Loop Control } & \multicolumn{2}{l|}{$\begin{array}{l}\text { Modified open Loop } \\
\text { Control }\end{array}$} \\
\cline { 2 - 5 } & $\mathrm{q}$ & $V_{\text {out }}$ & $\mathrm{q}$ & $V_{\text {out }}$ \\
\hline 100 & 0.4 & 40 & 0.4 & 40 \\
\hline 50 & 0.4 & 20 & 0.8 & 40 \\
\hline
\end{tabular}

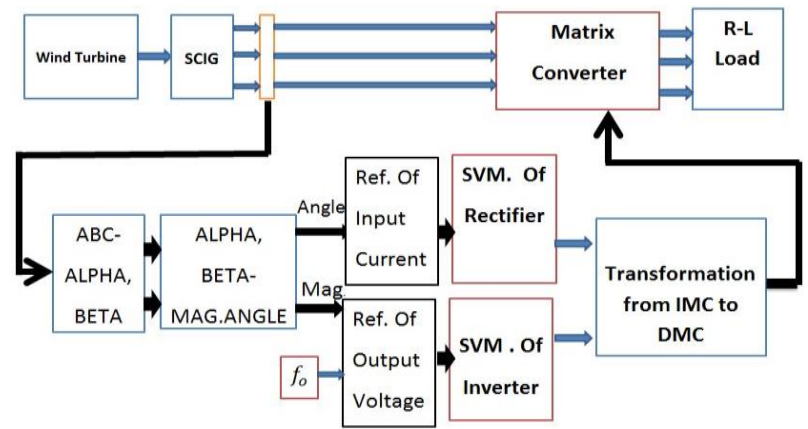

(a) block diagram of model

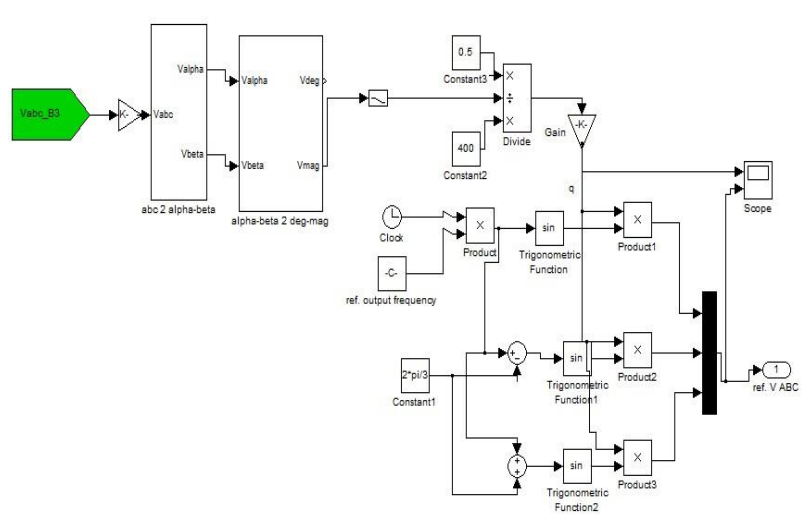

(b) Simulink of modification in the Model

Fig. 7. Modified open loop control 


\section{SIMULATION RESULTS}

Simulations were done using MATLAB/Simulink software package. The simulation results for a MC interfaced wind energy conversion system for an isolated $R-L \operatorname{load}(R=2 \Omega, L=1 \mathrm{mH})$ will be presented. The bidirectional switch used here is MOSFET and four ultra-fast diodes. The output filter used is LC filter with value of $L=2.3 \mathrm{mH}, \mathrm{C}=100 \mu \mathrm{f}$ [20]. To obtain the desired output voltage and frequency, the matrix converter is controlled by using indirect space vector modulation with modified open loop control. Figure 8shows simulation results at different wind speed with open loop control. Figure 9 shows simulation results at different wind speeds with modified open loop control, In case of a modified open loop control the output voltage and frequency remain constant to the desired value $220 \mathrm{~V}, 50 \mathrm{~Hz}$ output even if the wind speed changed. In case of open loop control the output voltage is a ratio of input voltage so if the output voltage changed with speed as shown in fig.8. Table 2 gives the magnitude of voltages and frequency with variation of wind speeds. Figure (8.a, 9.a) shows wind velocity with time, where the speed of wind changed from $7 \mathrm{~m} / \mathrm{s}$ to $12 \mathrm{~m} / \mathrm{s}$ at $t=0.3 \mathrm{sec}$, from $12 \mathrm{~m} / \mathrm{s}$ to $9 \mathrm{~m} / \mathrm{s}$ at $\mathrm{t}=0.6 \mathrm{sec}$, from $9 \mathrm{~m} / \mathrm{s}$ to 6 $\mathrm{m} / \mathrm{s}$ at $\mathrm{t}=1 \mathrm{sec}$. Figure $8 . \mathrm{b}$ shows input voltage to $\mathrm{MC}$ (generated voltage), Fig.8.c shows simulation results of output voltage of $50 \mathrm{~Hz}$ with open loop control. It's clear from fig.8.c that the magnitude of the output voltage isn't constant; Fig.8.d shows simulation results of output current of $50 \mathrm{~Hz}$ with open loop. Figure 9.b shows input voltage to MC (generated voltage), where for $t=0: 0.3 \mathrm{sec}$ the generated voltage is $320 \mathrm{~V}, 25 \mathrm{~Hz}$, where for $\mathrm{t}=0.3: 0.6 \mathrm{sec}$ the generated voltage is $460 \mathrm{~V}, 46 \mathrm{~Hz}$, where for $\mathrm{t}=0.6: 1$ sec the generated voltage is $380 \mathrm{~V}, 34 \mathrm{~Hz}$, where for $\mathrm{t}=1: 1.5 \mathrm{sec}$ the generated voltage is $280 \mathrm{~V}, 21 \mathrm{~Hz}$. Fig.9.c shows simulation results for the desired output voltage of $220 \mathrm{~V}, 50 \mathrm{~Hz}$ with modified open loop control. It's clear from fig.10.c that the magnitude of the output voltage is constant and equal to the reference value $=220 \mathrm{~V}$; Fig.9.d shows simulation results of output current of $50 \mathrm{~Hz}$ with modified open loop control.
Table 2. Variation of generated voltage and frequency with wind velocity

\begin{tabular}{|c|c|c|}
\hline Wind velocity $\mathrm{m} / \mathrm{s}$ & Voltage $(\mathrm{V})$ & Frequency $(\mathrm{Hz})$ \\
\hline 6 & 280 & 21 \\
\hline 7 & 320 & 25 \\
\hline 9 & 380 & 34 \\
\hline 12 & 460 & 46 \\
\hline
\end{tabular}

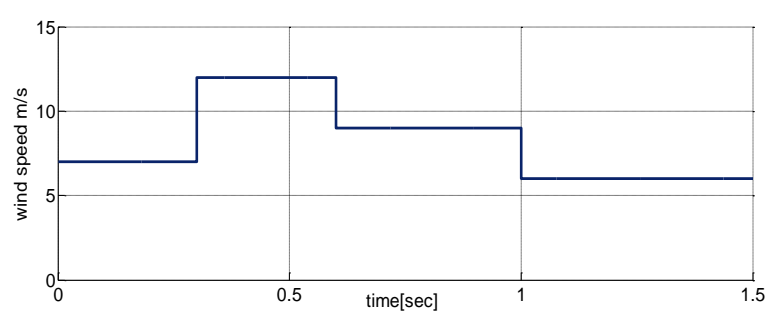

(a) Dynamic response of wind speed

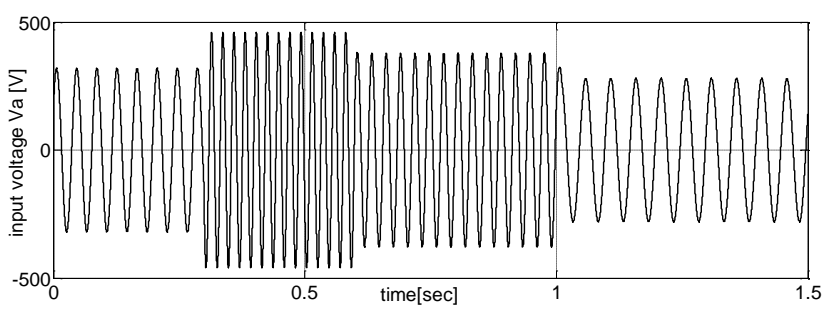

(b) Input voltage $V_{a}$ at different wind speeds

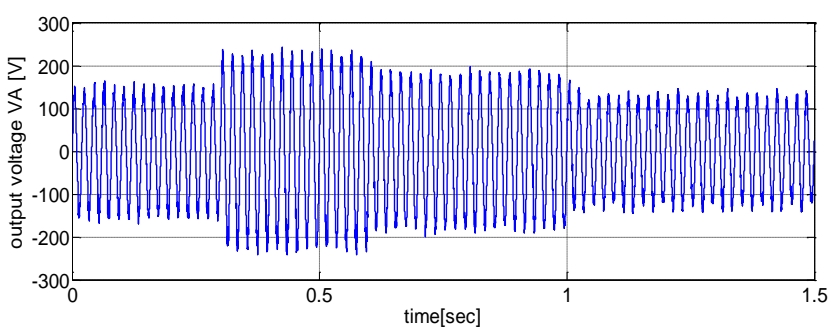

(c) Output voltage $V_{A} 50 \mathrm{~Hz}$

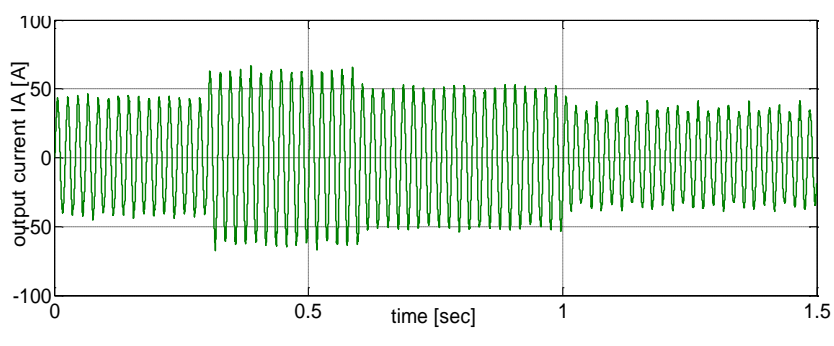

(d) Output current $I_{A} 50 \mathrm{~Hz}$

Fig. 8. Simulation results for open loop control of a matrix converter 


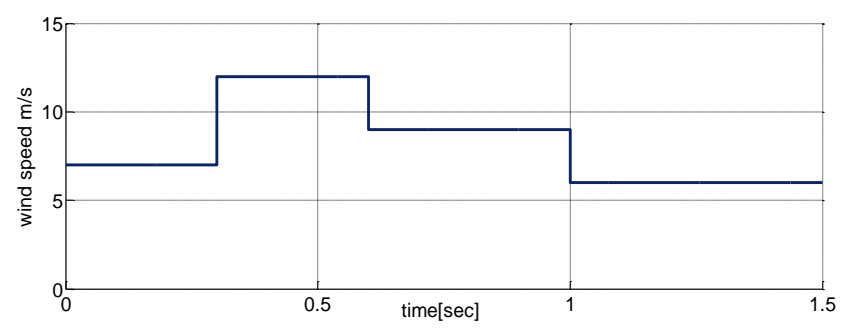

(a) Dynamic response of wind speed

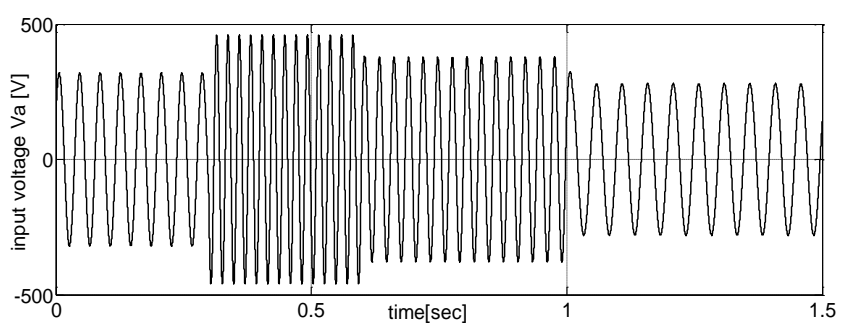

(b) Input voltage $V_{a}$ at different wind speeds

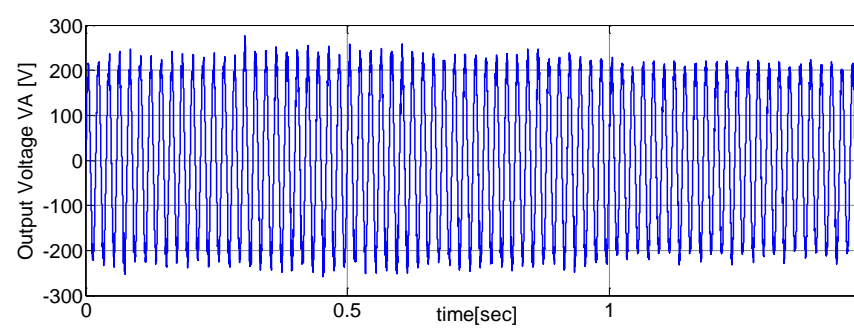

(c) Output voltage $V_{A} 50 \mathrm{~Hz}$

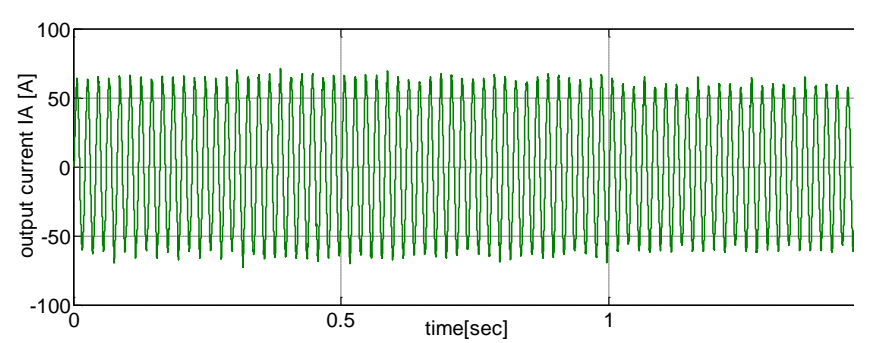

(d) Output current $I_{A} 50 \mathrm{~Hz}$

Fig. 9. Simulation results for modified open loop control of a matrix converter

Figure 10 show input displacement factor control, Fig.10-a shows unity input displacement factor, Fig.10-b show input displacement factor with displacement factor angle equal to $20^{\circ}$.

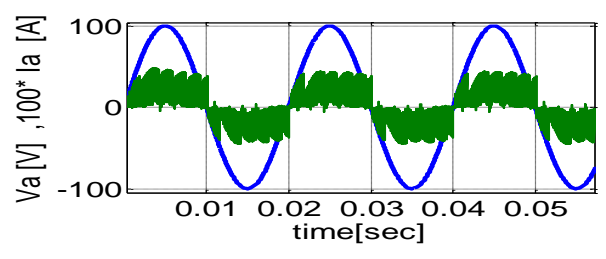

(a) Unity input displacement factor

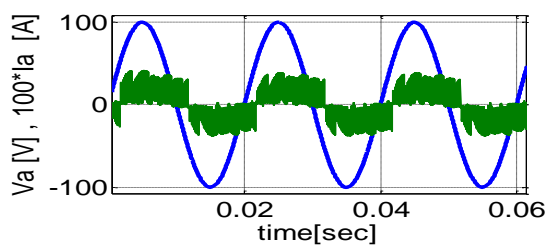

(b) Displacement factor of angle $20^{\circ}$

Fig.10. control of displacement factor

\section{EXPERIMENTAL RESULTS}

Experimental results were performed using DSP1104, with an isolated static load of $(R=20 \Omega, L=40 \mathrm{mH})$. The field and armature voltage of DC motor is controlled to control its speed to simulate wind turbine. Figure 11 show Experimental results for change in speed at a time $20 \mathrm{sec}$ in case of open loop control with $50 \mathrm{~Hz}$ output frequency, wherefig.11-a shows the change in speed where speed changes from $1535 \mathrm{rpm}$ to 1675 rpm by increasing the armature voltage. Figure 11-b shows the input voltage where the rms value and frequency of the input voltage increase with the increase in speed. Figure 11-c shows output voltage in case of open loop control .The rms value of the output voltage is a precent of the input voltage so the rms value of the output voltage changes with change in input voltage.

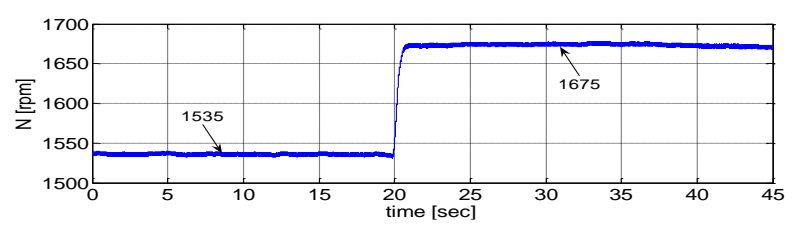

(a) Speed response

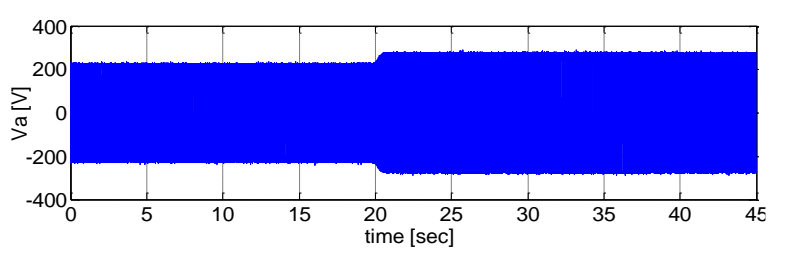

(b) Input voltage $V_{a}$

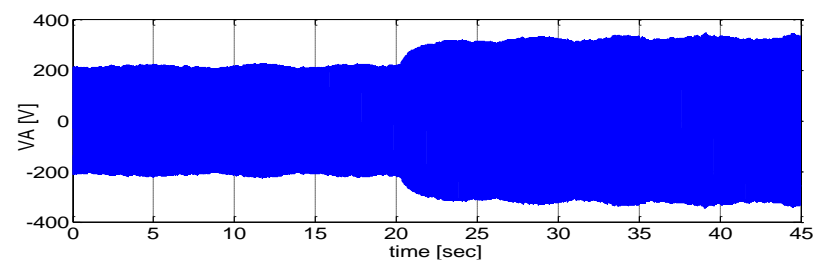

(c) Output voltage $V_{A}$

Fig. 11. Experimental results with open loop control \& output frequency $50 \mathrm{~Hz}$ 


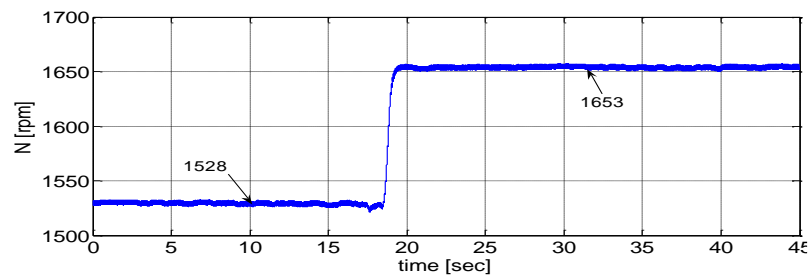

(a) Speed response

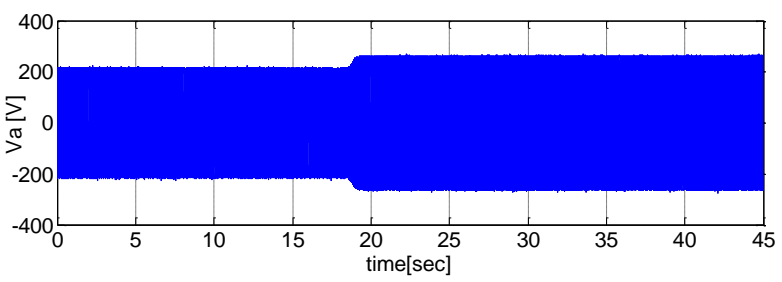

(b) Input voltage $V_{a}$

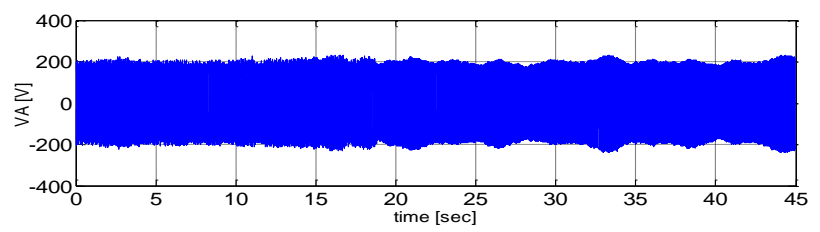

(c) Output voltage $V_{A}$

Fig .12. Experimental results with modified open loop control \& output frequency $50 \mathrm{~Hz}$

Figure 12 shows experimental results for change in speed at a time $18.5 \mathrm{sec}$ in case of modified open loop control with $50 \mathrm{~Hz}$ output frequency, where Figure 12-a shows the change in speed where speed changes from $1528 \mathrm{rpm}$ to $1653 \mathrm{rpm}$ by increasing the armature voltage. Figure 12-b shows the input voltage where the rms value and frequency of the input voltage increase with the increase in speed the input frequency increases from $30 \mathrm{~Hz}$ to $33.5 \mathrm{~Hz}$ approximately. Figure 12-c shows output voltage in case of modified open loop control .The output frequency doesn't change even if the input frequency changes.

\section{CONCLUSIONS}

In this paper, a modified open control of the indirect space vector modulation was introduced which improve the performance of matrix converter with variable speed operation of the wind turbine. The voltage and frequency of a static R-L load can be controlled by using a MC fed from wind energy conversion system. The angle between input voltage and input current of $\mathrm{MC}$ can be controlled and unity input displacement factor can be achieved. The analysis of indirect space vector modulation was introduced, in addition to introducing how to transform from indirect $M C$ to direct one. Model produces a very good wave form on output side. The simulation and experimental set up results are consistent with the expected results, where the direct converters have the ability to provide sinusoidal wave forms.

\section{REFERENCES}

[1] KotbB.Tawfiq,A.F.Abdou,E.E.EL-

Kholy,S.S.Shokralla "Perfo-rmance analysis of a matrix converter interfaced wind energy conversion system for static load application " ICNEEE , Cairo, Egypt 11-14 April 2016

[2] KotbB.Tawfiq, A.F.Abdou, E.E.EL-Kholy, S.S.Shokralla "A Modified Space Vector Modulation Algorithm for a Matrix Converter with Lower Total Harmonic Distortion "2016 IEEE 59th Midwest Symposium on Circuits and Systems,Abu Dhabi,United Arab Emirates.

[3] X. Zhang, W. Wang, D. Liu, H. Wang, X. Cao, S. He,"matrix wind turbine generator system "IEEE PEDS 2015, Sydney converter control study of doubly feed induction, Australia9 - 12 June 2015

[4] H. Hojabri, H. Mokhtari and L. Chang, "Reactive power control of permanent-magnet synchronous wind generator with matrix converter", IEEE Trans. Power Delivery., vol. 28, no. 2, pp.575584, April 2013.

[5] N. Holtsmark, S. Sanchez and M. Molinas, "Speed regulation ofa wind turbine with current source or matrix converter: tuning procedure", in Proc. IEEE 13th Worksop on Control and Modeling for Power Electronics (COMPEL), June 2012.

[6] R. Teodorescu, and F. Blaabjerg, "Flexible Control of Small Wind Turbines With Grid Failure Detection Operating in Stand-Alone and Grid Connected Mode", IEEE Trans. On Power Electronics, Vol. 19, NO. 5, SEP. 2004, pp. 1323, 1332.

[7] W. Lu and B. T. Ooi, "Multiterminal LVDC system for optimal acquisition of power in wind-farm using induction generators", IEEE Tran. On Power Electronics Vol. 17, NO. 4, JULY 2002, pp. 558-563. 
[8] Rajesh Kumar Thakur,Vivek Agarwal andPaluri S. V. Nataraj," A Reliable and Accurate Calculation of Excitation Capacitance Value for an Induction Generator Based on Interval Computation Technique," International Journal of Automation and Computing ,November 2011, ,pp.429-436.

[9] ALI M. EltAmALY, PhD," New Formula to Determine the Minimum Capacitance Required for Self-Excited Induction Generator," 33rd IEEE Power Electronics Specialists Conference, 23 27 June 2002 Cairns Convention Centre, Queensland, Australia, 2002.

[10] M. Venturini and A. Alesina, "The generalized transformer: A new bidirectional sinusoidal waveform frequency converter with continuously adjustable input power factor " in Proc. IEEE PESC'80, 1980, pp. 242- 252.

[11] P. W. Wheeler, IEEE, J. Rodríguez, J. Clare, L. Empringham, and A. Weinstein, " Matrix Converters: A Technology Review ", IEEE Trans. On Industrial elctronicas, Vol. 49, NO. 2, APRIL 2002,pp 276-289.

[12] S.M. Barakati, J.D Aplevich, M. Kazerani," controller design for a wind turbine system including a matrix converter", IEEE Power Engineering society General meeting, PP.1-8, 2007.

[13] J. G. Slootweg, S. W. H. de Haan, H. Polinder, and W. L. Kling, "General Model for Representing Variable Speed Wind Turbines in Power System Dynamics Simulations", IEEE Trans. On Power Systems, Vol. 18, NO. 1, FEB.2003, pp. 144-151.

[14] Ramasamy BHARANIKUMAR , A.Nirmal KUMAR,"performance analysis of wind turbinedriven permanent magnet generator with matrix converter",Turk J Elec Eng\&Comp Sci, Vol 20 no.3,2012.
[15] R. KumarThakur1 , V. Agarwal, P. S. V. Natara" A Reliable and Accurate Calculation of Excitation Capacitance Value for an Induction Generator Based on Interval Computation Technique " International Journal of Automation and Computing 8(4), November 2011, 429-436.

[16] Casadei, G. Grandi, G. Serra, A. Tani, "Space vector control of matrix converters with unity input power factor and sinusoidal input/output waveforms," Proceedings of IEEEPE' 93, Vol. 7, pp. 170-175, 1993.

[17] L. Gyugyi and B. R. Pelly, Static Power Frequency Changers: Theory, Performance, and App1ication, John Wiley \& Sons, 1976.E H. Miller, "A note on reflector arrays IEEE Trans. Antennas Propagat., to be published.

[18] Wheeler, P., J. Rodriguez, J. Clare, L. Empringham, and A. Weinstein, "Matrix converters: A technology review," IEEE Transactions on Power Electronics, Vol. 49, No. 2, 2002.

[19] J. Rodriguez, M. Rivera, J. W. Kolar and P. W. Wheeler, "A review of control and modulation methods for matrix converters", IEEE Trans. Ind. Electron., vol. 59, no. 1, pp. 58- 70, January 2012

[20] V. Vlatkovic,D. Borojevicand F. C. Lee, "Input Filter Design for Power Factor Correction Circuits,"IEEE Transaction on Power Electronics,pp.199-205,Jan199 